\title{
Effects of host plant quality on overwintering success of the leaf beetle Chrysomela lapponica (Coleoptera: Chrysomelidae)
}

\author{
ELENA L. ZVEREVA \\ Section of Ecology, Department of Biology, University of Turku, Turku FIN20014, Finland; e-mail: elezve@utu.fi
}

\begin{abstract}
Key words. Carbon, Chrysomela lapponica, Coleoptera, Chrysomelidae, delayed inducible resistance, hibernation, host-plant quality, nitrogen, pre-overwintering feeding, Salix myrsinifolia subsp. borealis, weight gain rate, overwintering mortality
\end{abstract}

\begin{abstract}
I investigated effects of density-dependent variation in host plant quality on adult feeding and overwintering success of the leaf beetle Chrysomela lapponica L. During pre-overwintering period adult beetles were fed in the laboratory on host plants, Salix borealis, originating from (a) a site with low density population of $C$. lapponica, (b) a site with peak density of $C$. lapponica, and (c) a post-outbreak site. Beetles fed on plants from low density and peak density sites demonstrated similar performance, whereas on plants from post-outbreak site beetles fed longer, gained more weight, and experienced greater mortality during overwintering. Higher water content in these beetles suggests that the main reason for increased winter mortality is insufficient dehydration of the beetles' bodies, presumably due to low quality food. The total carbon concentration in host plant foliage explained variation in most beetle performance indices, while total nitrogen did not correlate with beetle performance. Damage-induced decrease in quality of host plants from post-outbreak sites (delayed inducible resistance, DIR), associated with increase in carbon-containing defensive compounds, was earlier found to increase larval mortality and thus contribute to the decline in population density of $C$. lapponica. Results of the current study suggest that DIR can also disturb pre-overwintering feeding and thus increase winter mortality of adult beetles, enhancing post-outbreak density decline.
\end{abstract}

\section{INTRODUCTION}

Natural mortality of insects during overwintering may be very high, especially in northern areas (Danks, 1978; Hokkanen, 1993; Leather et al., 1993), resulting in significant effects on insect population dynamics (Green, 1962; Sullivan \& Wallace, 1972; Tenow \& Nilssen, 1990). Survival during overwintering depends on both environmental characteristics and internal physiological processes (Leather et al., 1993; Han \& Bauce, 1998). One of the major factors which determines the performance (in terms of survival, weight, development duration) and physiology of herbivorous insects, is the quality of their host plants (Scriber \& Slansky, 1981; Miller \& Miller, 1986; Karban \& Baldwin, 1997).

Changes in host-plant quality for herbivores, which are induced by plant damage from herbivory, have recently received much attention (reviewed by Karban \& Baldwin, 1997). The decrease in host plant quality, resulting from severe damage during previous year(s), is called delayed inducible resistance (DIR). Although DIR adversely affects many characteristics of herbivore performance (reviewed by Haukioja \& Neuvonen, 1987; Karban \& Baldwin, 1997), DIR impact on overwintering success has not been studied. DIR is an important factor in insect population dynamics: because DIR is a density-dependent function of herbivore damage (i. e. herbivore population size), it could provide the negative feedback necessary to regulate fluctuations in herbivore populations (Benz, 1974; Haukioja, 1990; Underwood, 1999).

Populations of the willow-feeding leaf beetle Chrysomela lapponica L. demonstrate pronounced density fluctuations (Zvereva et al., 1995a). Investigation of fac- tors affecting population dynamics of this species showed that natural enemies play a minor role in regulation of density dynamics (Zvereva \& Kozlov, 2000), while DIR may significantly contribute to density decrease after an outbreak (Zvereva et al., 1997). Changes in host plant quality induced by previous damage (particularly herbivore outbreak) resulted in reduced fecundity and preadult survival, increased duration of development, and disturbed feeding behaviour of C. lapponica (Zvereva \& Kozlov, 1996; Zvereva et al., 1997, 1998). Therefore I hypothesized that decrease in host plant quality (i. e. DIR) may increase winter mortality of beetles due to disturbance of pre-overwintering feeding. I tested this hypothesis by using host plants from sites where C. lapponica populations were on different stages of density fluctuation, assuming that in post-outbreak sites plants were of low quality due to DIR. Beetle performance during the period between hatching of summer generation and the beginning of diapause, as well as winter mortality were studied in C. lapponica beetles feeding on plants from the three sites.

\section{MATERIALS AND METHODS}

Study animals. Chrysomela lapponica, a medium sized (5-8 $\mathrm{mm}$ length) leaf beetle, in NW Russia clearly prefers Salix borealis (Fries) Nasar. which is common in the study area (Zvereva et al., 1995b). Adult beetles hibernate in soil and start feeding and copulating at the time of leaf flush, which in our study region occurs at about mid-June. Larvae feed on willow foliage from early July to early August and pupate on leaves. Beetles of the summer generation emerge in mid-August, feed for twothree weeks and then dig into the soil for overwintering. Overwintering biology of this species is unknown. 
TABLE 1. Effects of host-plant individual (Bush) and site of host-plant origin (Site) on characteristics of Chrysomela lapponica before and during overwintering (General Linear Model, the Type III Sum of Squares).

\begin{tabular}{|c|c|c|c|c|c|}
\hline Character & Source & df & Mean square & $\mathrm{F}$ & $\mathrm{P}$ \\
\hline \multirow[t]{3}{*}{ Fresh weight at the beginning of diapause } & Site & 2 & 22403.65 & 8.96 & 0.0002 \\
\hline & Bush(Site) & 12 & 6212.27 & 2.49 & 0.0041 \\
\hline & Error & 303 & 2499.81 & - & - \\
\hline \multirow[t]{3}{*}{ Fresh weight gain during pre-overwintering feeding } & Site & 2 & 1929.19 & 9.70 & $<0.0001$ \\
\hline & Bush(Site) & 12 & 986.10 & 4.96 & $<0.0001$ \\
\hline & Error & 303 & 198.91 & - & - \\
\hline \multirow[t]{3}{*}{ Fresh weight gain rate } & Site & 2 & 110.43 & 8.25 & 0.0003 \\
\hline & Bush(Site) & 12 & 42.32 & 3.16 & 0.0003 \\
\hline & Error & 300 & 13.39 & - & - \\
\hline \multirow[t]{3}{*}{ Fresh weight loss during overwintering } & Site & 2 & 208.85 & 2.38 & 0.10 \\
\hline & Bush(Site) & 12 & 353.65 & 4.03 & $<0.0001$ \\
\hline & Error & 210 & 87.69 & - & - \\
\hline \multirow[t]{3}{*}{ Fresh weight after overwintering } & Site & 2 & 109.12 & 6.04 & 0.0028 \\
\hline & Bush(Site) & 12 & 20.50 & 1.13 & 0.33 \\
\hline & Error & 210 & 18.17 & - & - \\
\hline \multirow[t]{3}{*}{ Dry weight after overwintering } & Site & 2 & 0.43 & 0.35 & 0.70 \\
\hline & Bush(Site) & 12 & 1.24 & 1.01 & 0.44 \\
\hline & Error & 196 & 122.54 & - & - \\
\hline \multirow[t]{3}{*}{ Water content in beetles } & Site & 2 & 1.433 & 9.48 & 0.0001 \\
\hline & Bush(Site) & 12 & 4.45 & 3.01 & 0.0007 \\
\hline & Error & 196 & 29.60 & - & - \\
\hline \multirow[t]{3}{*}{ Duration of pre-overwintering feeding } & Site & 2 & 9.94 & 3.96 & 0.02 \\
\hline & Bush(Site) & 12 & 1.20 & 0.48 & 0.93 \\
\hline & Error & 300 & 2.51 & - & - \\
\hline \multirow[t]{2}{*}{ Mortality during overwintering* } & Site & 2 & 490.68 & 6.39 & 0.01 \\
\hline & Error & 12 & 76.73 & - & - \\
\hline
\end{tabular}

*Since mortality was calculated on plant-specific level, effect of individual plant within site could not be calculated.

Population densities of $C$. lapponica in ten study sites located from $16 \mathrm{~km} \mathrm{NE}$ to $36 \mathrm{~km} \mathrm{~S}$ of the city of Monchegorsk (Kola Peninsula, NW Russia, 67 $52^{\prime} \mathrm{N}, 32^{\circ} 48^{\prime} \mathrm{E}$ ) were recorded in mid-June in 1991-1999 by 10-min counts of overwintered beetles, three counts per site (for details, see Zvereva et al., 1995a, b). In some sites densities remained nearly constant during the entire monitoring period, whereas in other sites I observed significant density fluctuations (up to 300 -fold change), with the peak values attained at different years (Zvereva et al. 1995a, 1997, Zvereva \& Kozlov 2000).

Study sites and host plants. To study the effects of damageinduced changes in host plant quality on overwintering of $C$. lapponica, I fed beetles in the laboratory on the foliage of 15 individuals of $S$. borealis from three study sites (five plants per site). These sites differed in characteristics of leaf beetle populations: (i) a site with non-fluctuating low-density population, which showed no significant density changes since 1991 (low density site hereafter); (ii) a site with fluctuating population on the stage of density increase, or peak density (peak density site); (iii) a fluctuating population on the stage of post-outbreak density decline (post-outbreak site).

Experimental design. About 500 last-instar larvae of C. lapponica, collected on July 20,1998, in the peak density site, were fed in the laboratory on foliage of $S$. borelais from the lowdensity site (i. e. not damaged during the current or in the previous years) until pupation. After hatching, which occurred July $27-30$, each beetle was placed in a $50 \mathrm{ml}$ vial and randomly allocated to one of the 15 study plants, $20-25$ beetles per plant
(347 in total). Fresh willow leaves were added to vials every day, and the day when injuries on the foliage were not found was considered as the day of feeding cessation and the beginning of diapause. On August 25 fresh sphagnum moss was added to each vial, and vials were placed for overwintering into a cellar, where the temperature did not fall below $-5^{\circ} \mathrm{C}$. In spring (May 15) beetles were removed from the cellar and each beetle was classified as dead or alive.

Each beetle was weighed (i) immediately after hatching and hardening, before the start of feeding (WH, weight at hatching), (ii) the next day after beetles stopped feeding and emptied the gut (WD, weight at the beginning of diapause), and (iii) after overwintering (WO), before beetles started feeding (May 1999) (survivors only). Dry weight of the beetles that survived after overwintering (DW) was determined after drying at $60^{\circ} \mathrm{C}$ to constant weight in air. Duration of pre-overwintering feeding was recorded (D). Several parameters were calculated: weight gain during pre-overwintering feeding, $\mathrm{WG}=(\mathrm{WD}-\mathrm{WH}) / \mathrm{WH}$; weight gain rate during pre-overwintering feeding, WGR = $\mathrm{WG} / \mathrm{D}$; weight loss during overwintering, $\mathrm{WL}=$ (WOWD $) / \mathrm{WD}$; and body water content $=(\mathrm{WO}-\mathrm{DW}) / \mathrm{WO}$.

Carbon and nitrogen analysis. A sample of leaves was collected from each of 15 individuals of $S$. borealis; leaves were taken from the middle part of the shoots to avoid affects of leaf age. Leaves were dried at $80^{\circ} \mathrm{C}$ and then ground. Plant-specific total carbon and nitrogen were analyzed by LECO CHN-1000 Macrosample Elemental Analyser (LECO Corporation, St. Joseph, Michigan). 

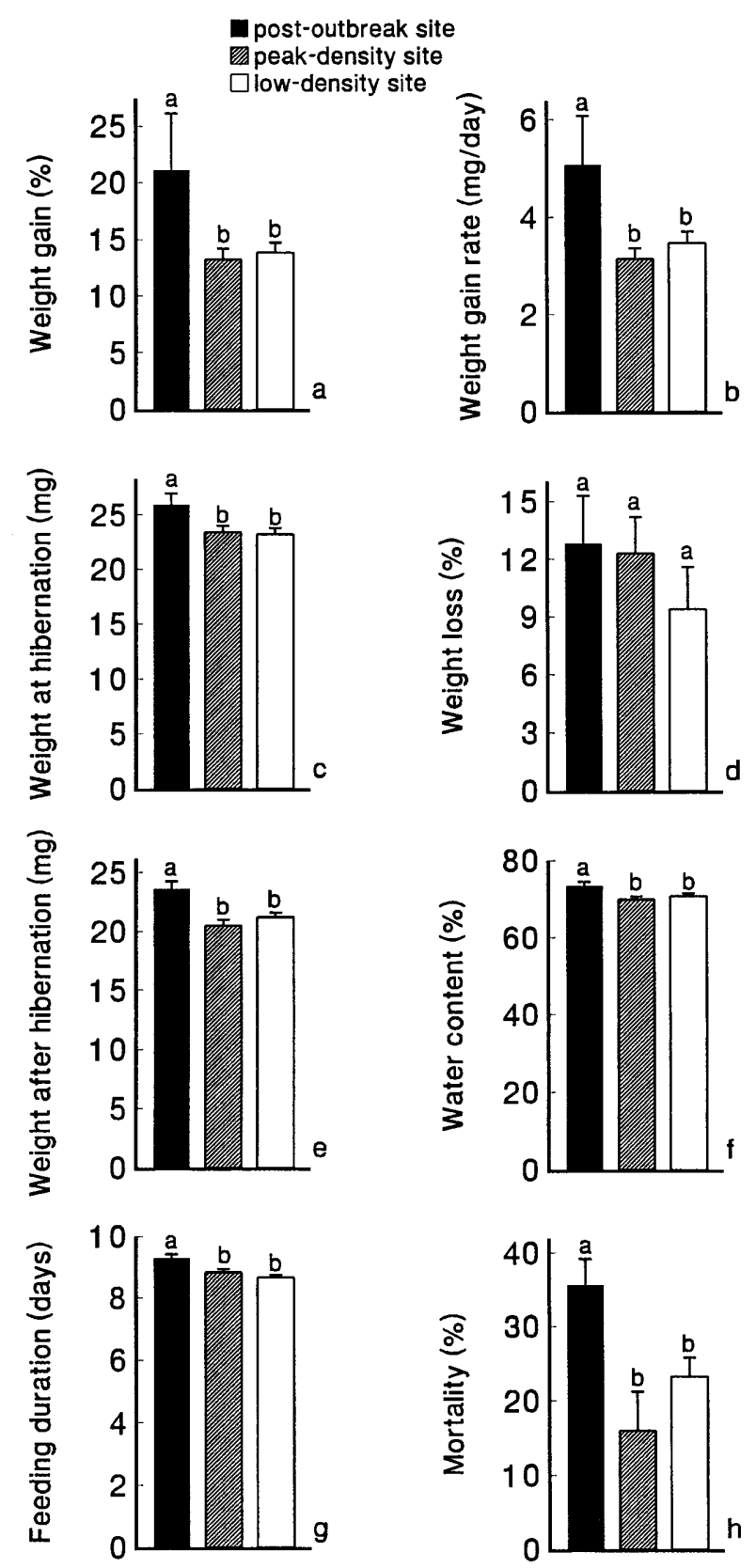

Fig. 1. Effect of the site of host-plant origin on performance indices of Chrysomela lapponica. $\mathrm{a}$ - beetle fresh weight gain; $\mathrm{b}$ - weight gain rate during pre-overwintering feeding; $\mathrm{c}$ - beetle fresh weight at the beginning of overwintering; $d$ - weight loss during overwintering; e - fresh weight after overwintering; f body water content; $g$ - duration of pre-overwintering feeding; $\mathrm{h}-$ beetle mortality during overwintering. Sites differ in the stage of $C$. lapponica population density fluctuation: postoutbreak site, peak-density site and low-density site. Each mean is based on five plant-specific values; bars indicate standard errors. Bars marked with different letters differ from each other at the probability level $P<0.05$ (Duncan's multiple range test).

Data analysis. Effects of host-plant individual and of the site of plant origin on leaf beetle characteristics were analyzed using the General Linear Model (type III sum of squares); site-specific means were compared with Duncan's multiple range test. Beetle mortality during overwintering was assessed at the plantspecific level, and therefore only the effect of site could be assessed. Normality of all variables was checked by SAS UNI-
VARIATE procedure and variables not fitting normality assumption were $\ln (x+1)$ transformed. Correlations between beetle characteristics and the total carbon and nitrogen content of the host plant were calculated on plant-specific level by Pearson's correlation coefficient (SAS, 1990).

\section{RESULTS}

Both the site of host-plant origin and plant individual affected beetle weight at the beginning of diapause, as well as weight gain and weight gain rate during preoverwintering feeding (Table 1). Weight loss varied with plant individual, but was not explained by the site of plant origin. In contrast, duration of pre-overwintering feeding depended on host-plant site, but did not depend on among-plant variations within a site. The site of host plant origin affected winter mortality (Table 1). Beetles that fed on plants from the post-outbreak site gained more weight compared to beetles fed on plants from lowdensity or peak-density sites (Fig. 1a, c). Higher weight was attained due to both longer period of feeding and higher weight gain rate (Fig. $1 \mathrm{~b}, \mathrm{~g}$ ). Weight loss in beetles that survived during overwintering was similar in all study sites (Fig. 1d). Therefore, surviving beetles fed on post-outbreak plants had higher weight after overwintering (Fig. 1e), mostly due to higher water content in their bodies (Fig. 1f), whereas dry weight of the beetles did not depend on host plant quality (Table 1). Beetles which fed on plants from post-outbreak site suffered higher winter mortality (Fig. 1h).

Although total carbon content in foliage of $S$. borealis was similar in the three study sites $\left(F_{2,12}=0.30, P=\right.$ $0.75)$, weight gain, weight gain rate, weight at the beginning of overwintering, and duration of pre-overwintering feeding positively correlated with plant-specific concentrations of carbon (Fig $2 \mathrm{a}, \mathrm{c}, \mathrm{e}, \mathrm{g}$ ). In contrast, total plant nitrogen varied among study sites $\left(F_{2,12}=19.9, P=\right.$ 0.0002 ), but did not explain any of the studied beetle characteristics (Fig. 2b, d, f, h).

\section{DISCUSSION AND CONCLUSIONS}

\section{Effect of pre-overwintering feeding on winter mortality}

Overwintering mortality in insects may result from both inadequate cold hardiness preparation and exhaustion of energy reserves, which both can be significantly influenced by pre-winter conditions (Leather et al. 1993; Han \& Bauce, 1998). Individuals that accumulate larger amounts of nutritive reserves during pre-overwintering feeding have usually higher probability to survive during the overwintering. For example, heavy individuals of Meligethes aeneus overwintered successfully, whereas low-weight beetles did not survive (Hokkanen, 1993). In contrast, C. lapponica beetles, which fed on plants from post-outbreak site and gained higher wet weight, showed larger winter mortality. Comparison of dry weight allowed the explanation of the high weight of these beetles by higher water content in beetle body.

Body water plays an important role in arthropod cold hardiness: partial dehydration, which in many arthropods is a necessary part of preparation for overwintering (Salt, 

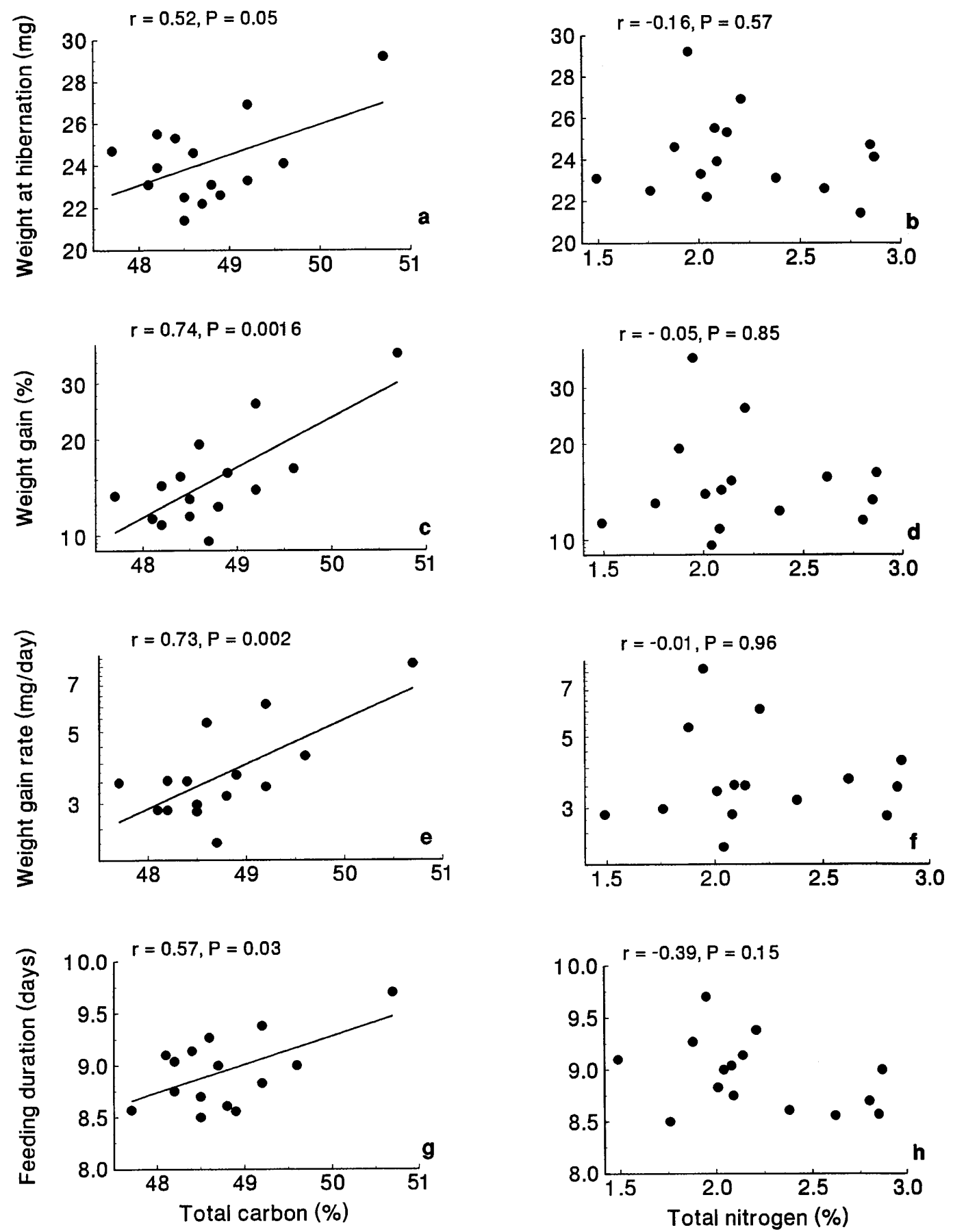

Fig. 2. Fresh beetle weight at the beginning of overwintering (a, b), pre-overwintering fresh weight gain (c, d); weight gain rate (e, $\mathrm{f})$; and duration of pre-overwintering feeding ( $\mathrm{g}, \mathrm{h}$ ) of Chrysomela lapponica in relation to total carbon (a, c, e, g) and total nitrogen $(\mathrm{b}, \mathrm{d}, \mathrm{f}, \mathrm{h})$ in Salix borealis foliage. Pearson's correlation coefficient is calculated on the basis of 15 plants-specific values.

1956; van der Laak, 1982; Ring, 1982; Block, 1996; Danks, 2000), may significantly affect cold resistance in both freezing tolerant and freezing susceptible forms (Block, 1996) by increasing cryoprotectant concentrations and reducing ice nucleator activity (Gehrken, 1985; Rickards et al., 1987; Pugh, 1994; Lee et al., 1996). Respectively, high body water content negatively affects cold hardiness and winter survival in insects (Vengorek, 1958; Cannon et al., 1985). Therefore it is likely that high water content in high-weight beetles of $C$. lapponica may be the main reason of increased winter mortality in popu- lations feeding on plants from post-outbreak sites. It may be suggested that individuals, which died during overwintering, had even higher water content than the survivors, and this excess of water caused their death.

Many factors influence the body water content of insects; in particular, feeding activity (Block, 1996) and food quality (House, 1969; Murugan \& George, 1992). For example, phytophagous larvae of the spurge hawk moth Celerio euphorbiae (L.) had higher water content when fed on unbalanced artificial diet, whereas proportion of water in the diet had no effect on body water con- 
tent in larvae (House, 1969). Body water content in Colorado potato beetle at the beginning of diapause was higher in beetles with a longer pre-overwintering feeding period, and these beetles suffered higher winter mortality (Kovalska, 1958; Ushatinskaya, 1981). However, to the best of my knowledge, almost nothing is known about the links between host-plant characteristics and overwintering success of herbivores.

\section{Plant characteristics affecting pre-overwintering feeding}

Earlier studies demonstrated that individuals of $S$. borealis growing in post-outbreak sites are poor quality food for both larvae and adults of $C$. lapponica. On these plants, larvae demonstrated higher mortality and lower consumption rates which resulted in prolonged development and lower pupal weight (Zvereva et al., 1997); adults also exhibited disturbed feeding behavior (Zvereva \& Kozlov, 1996; Zvereva et al., 1998). All these studies demonstrated that decrease in host-plant quality was caused by herbivore damage during outbreak, i.e. damaged plants have developed delayed inducible resistance (DIR). The definition of DIR is based on the effects observed in herbivores, and contains no assumptions about plant characteristics responding to damage (Haukioja, 1990; Karban \& Baldwin, 1997). Alterations in plant chemistry most frequently underly DIR (Karban \& Baldwin, 1997), but physical plant characteristics (such as specific leaf weight, thoughness, fibre content, pubescence, spininess) may also change in response to herbivory (Baur et al., 1991; Tallamy \& Raupp, 1991; Trumble et al., 1993). In S. borealis, the low quality of previously damaged plants (DIR) was largely explained by changes in leaf physical traits, including increase in leaf thickness, toughness, hairiness, and proportion of unconsumable bulk in leaf tissues (Zvereva et al., 1998; Zvereva, unpublished). These changes may cause nutrient deficiencies related to an increased proportion of fiber (Agarwall, 1969) and can reduce food intake. Chrysomela lapponica beetles preparing for overwintering seem to be trying to compensate decreased food intake on tough and hairy plants from post-outbreak site by longer feeding. However, higher winter mortality indicates that beetles failed to compensate for the nutrient deficiency. This result is in line with the data on larval feeding: although larvae of $C$. lapponica fed longer on induced $S$. borealis, they had still gained lower weight at pupation and suffered higher mortality (Zvereva et al., 1997).

Among-plant variation in weight gain and feeding duration of $C$. lapponica were not explained by total foliar nitrogen, which often serves as a measure of host-plant quality for herbivores (e.g. Mattson, 1980). In contrast, the feeding characteristics of $C$. lapponica were correlated with total foliar carbon. High carbon content in a plant is traditionally attributed to increased resource allocation to carbon-containing secondary compounds usually functioning as defense (also induced) against herbivores (Coley et al., 1985; Herms \& Mattson, 1992; Karban \& Baldwin, 1997). But in S. borealis, induced defences can unlikely be attributed to allelochemicals (Zvereva \&
Kozlov, 1998; Zvereva \& Orians, unpublished data). Besides high content of some secondary chemicals, higher carbon in leaves may indicate an increase in structural carbohydrates (i. e. "fibre"), such as cellulose, which are closely correlated to leaf toughness. Since induced willows are more hairy and tough, the high content of structural carbohydrates in these plants may be the most plausible explanation for strong correlation between preoverwintering beetle performance and total foliar carbon found in C. lapponica. Although the mechanism leading to increased water content in beetles feeding on tough plants remains unknown, it may be related to increased feeding duration in attempts to compensate low consumption rates and nutritive deficiency.

\section{Consequences for population dynamics}

Although DIR is considered an important factor regulating herbivore population dynamics (Underwood, 1999), some calculations show that adverse effects of DIR on pre-adult insect performance are not enough to cause significant density decline (Kaitaniemi et al., 1999). Effect of DIR on survival of non-feeding stages was overlooked in earlier studies, although food quality in preoverwintering period may have strong impact on survival of overwintering insects. Absolute values of winter mortality were relatively low in my experiments, where temperatures did not drop below $-5^{\circ} \mathrm{C}$, but detrimental effects of DIR on overwintering survival of $C$. lapponica may be much more dramatic in the natural environment, where minimum temperatures of the upper soil layer may reach $-20^{\circ} \mathrm{C}$ (Kozlov \& Haukioja, 1997). In these conditions, an increase in body water content may have a more severe impact on insect survival, via changes in supercooling capacity, than it was observed in the mild conditions of my experiment.

Besides the direct effect of DIR on the mortality of overwintering beetles due to physiological reasons, increased duration of pre-overwintering feeding in nature prolongs exposure to predation in autumn, when birds feed especially actively. The results of my study indicate that an increase in winter mortality caused by DIR may contribute significantly to total generation mortality. In combination with other detrimental effects of DIR, such as reduction in fecundity and larval mortality, adult mortality during overwintering may lead to considerable population density decline after outbreak.

ACKNOWLEDGEMENTS. I thank Dmitry Novikov for assistance in the laboratory work, Arja Tervahauta for the analysis of carbon and nitrogen in willow leaves, and M. Kozlov for valuable comments to an earlier draft of the manuscript. The work was supported by Maj and Tor Nessling Foundation, Turku University Foundation, and University of Joensuu (via grant to P. Niemelä).

\section{REFERENCES}

Agarwall R.A. 1969: Morphological characteristics of sugar cane and insect resistance. Entomol. Exp. Appl. 12: 767-776.

Baur R., Binder S. \& Benz G. 1991: Nonglandular leaf trichomes as short-term inducible defence of the gray alder, 
Alnus incana (L.), against chrysomelid beetle, Agelastica alni L. Oecologia 87: 219-226.

BENZ G. 1974: Negative feedback by competition for food and space, and by cyclic induced changes in the nutritional base as regulatory principles in the population dynamics of the larch budworm, Zeiraphera diniana (Guenee) (Lep.: Tortricidae). Z. Angew. Entomol. 76: 196-228.

BLock W. 1996: Cold or draught - the lesser of two evils for terrestrial arthropods? Eur. J. Entomol. 93: 325-339.

Cannon R.J., Block W. \& Collett G.D. 1985: Loss of supercooling ability in Cryptopygus antarcticus (Collembola: Isotomidae) associated with water uptake. Cryo-Letters 6: 73-80.

Coley P.D., Bryant J.P. \& Chapin F.S.III 1985: Resource availability and plant antiherbivore defense. Science 230: 895-899.

DANKS H.V. 1978: Modes of seasonal adaptation in the insects I. Winter survival. Can. Entomol. 110:1167-1205.

Danks H.V. 2000: Dehydration in dormant insects. J. Insect Physiol. 46: 837-852.

GeHrKen U. 1985: Physiology and diapause of the adult bark beetle, Ips acuminatus Gyll., studied in relation to cold hardiness. J. Insect Physiol. 31: 909-916.

GreEN G.W. 1962: Low winter temperatures and the European pine shoot moth, Rhyacionia buoliana (Schiff.) in Ontario. Can. Entomol. 94: 314-336.

HAN E.-N. \& BaUSE E. 1998: Timing of diapause initiation, metabolic changes and overwintering survival of the spruce budworm, Choristoneura fumiferana. Ecol. Entomol. 23: $160-167$

Haukioja E. 1990: Induction of defenses in trees. Anmu. Rev. Entomol. 36: 25-42.

Haukiora E. \& NeUvonen S. 1987: Insect population dynamics and induction of plant resistance: The testing of hypotheses. In: Barbosa P. \& Schultz J.C. (eds): Insect Outbreaks. Academic Press, San Diego, USA, pp. 411-432.

Herms D.A. \& Mattson W.J. 1992: The dilemma of plants: to grow or to defend. Q. Rev. Biol. 67: 283-335.

HoKKANEN H.M.T. 1993: Overwintering survival and spring emergence in Meligethes aeneus: effects of body weight, crowding, and soil treatment with Beauveria bassiana. Entomol. Exp. Appl. 67: 241-246.

House H.L. 1969: Effects of different proportions of nutrients on insects. Entomol. Exp. Appl. 12: 651-669.

Kaitaniemi P., Neuvonen S. \& Nryssönen T. 1999: Effects of cumulative defoliations on growth, reproduction, and insect resistance in mountain birch. Ecology 80: 524-532.

KARBAN R. \& BALDWIN J.T. 1997: Induced Responses to Herbivory. The University of Chicago Press, Chicago, USA, 319 pp.

Kozlov M.V. \& Haukioja E. 1997: Microclimate changes along a strong pollution gradient in northern boreal forest zone. In: Uso J.L., Brebbia C.A. \& Power H. (eds): Ecosystems and Sustainable Development. (Advances in Ecological Sciences, Vol. 1). Computation Mechanics Publications, Southampton, UK, pp. 603-614.

KovalSKA T. 1958: Effect of pre-overwintering physiological state of the Colorado potato beetle (Leptinotarsa decemlineata Say) on diapause and mortality during overwintering. In: Pavlovsky E.N. (ed.): Colorado Potato Beetle and Methods of its Control, Issue 2. Academy of Science of the U.S.S.R. Publ. House, Moscow, pp. 66-73. [in Russian]

Leather S.R., Walters K.F.A. \& Bale J.S. 1993: The Ecology of Insect Overwintering. Cambridge Univ. Press, Cambridge, $155 \mathrm{pp}$.
Lee R.E., Costanzo J.P. \& Mugnano J.A. 1996: Regulation of supercooling and ice nucleation in insects. Eur. J. Entomol. 93: $405-418$.

MatTSON W.J.Jr 1980: Herbivory in relation to plant nitrogen content. Anmu. Rev. Ecol. Syst. 11: 119-161.

Miller J.R. \& Miller T.A. (eds) 1986: Insect-Plant Interactions. Springer-Verlag, New York, $342 \mathrm{pp}$.

Murugan K. \& George A. 1992: Feeding and nutritional influence on growth and reproduction of Daphnis nerii (Linn.) (Lepidoptera: Sphingidae). J. Insect Physiol. 38: 961-967.

PuGH P.J.A. 1994: Supercooling points and water content in Acari. Acta Oecol. 15: 71-77.

Rickards J., Kellener M.J. \& Storey K.B. 1987: Strategies of freeze avoidance in larvae of the goldenrod gall moth, Epiblema scudderiana: winter profiles of a natural population. $J$. Insect Physiol. 33: 443-450.

RING R.A. 1982: Freezing-tolerant insects with low supercooling points. Comp. Biochem. Physiol. 73A: 605-612.

SALT R.W. 1956: Influence of moisture content and temperature on cold-hardiness of hibernating insects. Can. J. Zool. 34: 283-294.

SAS Institute 1990: SAS/STAT User's Guide, Version 6.0. SAS Institute, Cary, Northern Carolina, USA, $1286 \mathrm{pp}$.

SCRIBer J.M. \& Slansky F.Jr 1981: The nutritional ecology of immature insects. Annu. Rev. Entomol. 26: 183-211.

Sullrvan C.R. \& WALLACE D.R. 1972: The potential northern dispersal of the gypsy moth, Porthetria dispar (Lepidoptera: Lymantriidae). Can. Entomol. 104: 1349-1355.

Tallamy D.W. \& Raurpp M.J. (eds) 1991: Phytochemical Induction in Herbivores. J.Wiley \& Sons, New York, 431 pp.

TenOw O. \& Nilssen A. 1990: Egg cold hardiness and topoclimatic limitations to the outbreaks of Epirrita autumnata in northern Fennoscandia. J. Appl. Ecol. 27: 723-734.

Trumble J.T., Kolodny-Hirsch D.M. \& Ting I.P. 1993: Plant compensation for arthropod herbivory. Annu. Rev. Entomol. 38: $93-119$.

UNDERWOOD N. 1999: The influence of induced resistance on herbivore populations. In: Agraval A.A., Tuzun S. \& Bent E. (eds): Induced Plant Defenses against Pathogens and Herbivores. APS Press, St.Paul, Minnesota, USA, pp. 211-229.

Ushatrnskaya R.S. 1981: Colorado Potato Beetle, Leptinotarsa decemlineata Say. Phylogeny, Morphology, Physiology, Ecology, Adaptation, Natural Enemies. "Nauka", Moscow, 375 pp. [in Russian]

VAN DER LAAK S. 1982: Physiological adaptations to low temperature in freezing-tolerant Phyllodecta laticollis beetles. Comp. Biochem. Physiol. 73A: 613-620.

VENGOREK V. \& WEGGOREK W.1958: The study of overwintering of the Colorado potato beetle on the base of it's physiology. In: Pavlovsky E.N. (ed.): Colorado Potato Beetle and Methods of its Control, Issue 2. Academy of Science of the U.S.S.R. Publ. House, Moscow, pp. 53-65. [in Russian]

ZVEREVA E.L. \& KozLov M.V. 1996: Avoidance of willows from moderately polluted area by leaf beetle, Melasoma lapponica (Coleoptera: Chrysomelidae): effects of emission or induced resistance? Entomol. Exp. Appl. 79: 355-362.

ZVEREVA E.L. \& KozLov M.V. 2000: Effects of pollution on natural enemies of the leaf beetle, Melasoma lapponica. $J$. Appl. Ecol. 37: 298-308.

Zvereva E.L., Kozlov M.V. \& Neuvonen S. 1995a: Population density and performance of Melasoma lapponica (Coleoptera: Chrysomelidae) in surroundings of smelter complex. Environ. Entomol. 24: 707-715.

Zvereva E.L., Kozlov M.V. \& Neuronen S. 1995b: Decrease in feeding niche breadth of Melasoma lapponica (Coleoptera: 
Chrysomelidae) with increase in pollution. Oecologia 104: 323-329.

Zvereva E.L., Kozlov M.V., Niemelä P. \& Haukioja E. 1997: Delayed induced resistance and increase in leaf fluctuating asymmetry as responses of Salix borealis to insect herbivory. Oecologia 102: 368-373.
Zvereva E.L., Kozlov M.V. \& Niemelä P. 1998: Effects of leaf pubescence in Salix borealis on host-plant choice and feeding behaviour of the leaf beetle, Melasoma lapponica. Entomol. Exp. Appl. 89: 297-303.

Received November 9, 2001; revised January 30, 2002; accepted March 6, 2002 